\title{
Two-Years Follow-up Results of a Smoking Cessation Clinic in a State Hospital
}

\author{
Sami Deniz ${ }^{1}$, Jülide Çeldir Emre², Özer Özdemir ${ }^{3}$, Ayşegül Baysak ${ }^{4}$ \\ ${ }^{1}$ Didim State Hospital, Clinic of Chest Diseases, Aydın, Turkey \\ ${ }^{2}$ Turgutlu State Hospital, Clinic of Chest Diseases, Manisa, Turkey \\ ${ }^{3}$ Egepol Hospital, Clinic of Chest Diseases, İzmir, Turkey \\ ${ }^{4}$ Department of Chest Diseases, İzmir University School of Medicine, İzmir, Turkey
}

\begin{abstract}
Objective: The primary aim of the present study was to evaluate the data and success of a smoking cessation clinic in a secondary state hospital. Secondarily, the study aimed to compare the cessation rates of patients using varenicline and bupropion.

Methods: A total of 251 patients, admitted to our smoking cessation clinic were retrospectively evaluated. The smoking cessation clinic was run one day every week and included a 35-min presentation on smoking cessation and face-to-face interviews with every patient who attended the clinic. Monthly control visits were conducted, and after 2 years all the patients were asked about their smoking status via a phone call.
\end{abstract}

Results: A total of 152 out of the 251 patients, namely those who were successfully contacted, were included in the study. The average age of the study population was $46.2 \pm 11.2$ (18-69), and 81 (53.3\%) were female. The average nicotine dependence level was 5.8 \pm 2.3 . The nicotine dependence levels and the amount of current cigarette consumption in one day were higher in the varenicline group $(\mathrm{p}=0.003$ and $\mathrm{p}=0.002$, respectively), whereas the duration of treatment was lower ( $\mathrm{p}=0.009)$. Among all the patients, the average smoking cessation rate was $61.2 \%$ in 6 months, 34.2\% in 12 months, $18.4 \%$ in 18 months, and 5.3\% in 24 months. There were no differences in smoking cessation rates between the varenicline and bupropion groups $(p>0.05)$.

Conclusion: An effective success in smoking cessation was observed with the combined use of behavioral and pharmacological modalities. Intensive behavioral interventions and treatment and follow up for longer durations, particularly for patients with risk factors for relapse, can increase the success of smoking cessation clinics.

Keywords: Smoking, smoking cessation interventions, tobacco

Received Date: 28.09.2015 Accepted Date: 26.01 .2016 Available Online Date: 14.03.2016

DOI: 10.5152/ejp.2016.69885

Correponding Author

Sami Deniz

E-mail: sami_deniz@yahoo.com

- Available online at www.eurasianjpulmonol.com 4.0 International License.

\section{INTRODUCTION}

Tobacco dependence is one of the most important preventable causes of death in the world. According to World Health Organization (WHO) data, half of regular smokers prematurely die because of tobacco-related diseases (1). Worldwide, tobacco kills 6 million people every year, and it is estimated that tobacco dependence results in economic losses of more than half a trillion dollars annually. In Turkey, every year 100,000 people are killed because of tobacco, and this number is expected to increase to 240,000 by 2030 (2).

Six evidence-based tobacco control policies were implemented and enforced by WHO in 2008 (MPOWER package) (3). Although no country had protected its population with all four of the MPOWER measures by the year 2007, currently, Turkey has achieved an important success in being the first country to attain the highest level of achievement in all six measures (1). According to the $2008 \mathrm{Global}$ Adult Tobacco Survey Turkey Report, smoking prevalence in the adult population (15 or over) in Turkey was found to be $31.2 \%$ (48\% in men and $15 \%$ in women) (4). In 2012, updated data showed that smoking prevalence decreased to $27.1 \%$ (41.5\% in men and $13.1 \%$ in women) (5). Although this $13.4 \%$ relative decrease in smoking prevalence $(13.7 \%$ in men and $13.5 \%$ in women) is remarkable, more than a quarter of the adult population still regularly use tobacco products. 
Social consciousness regarding tobacco control has improved by the implementation of effective measures, improvements in legal regulations, and easy access to professional smoking cessation aids. In the present study, we examined the data of a smoking cessation clinic of a state hospital conducted by a pulmonary specialist, derived the overall success of smoking cessation interventions, and compared the data relating to patients using varenicline versus bupropion as a pharmacological therapy.

\section{METHODS}

Two hundred and fifty one patients who were admitted to the smoking cessation clinic of a secondary state hospital between August 2012 and April 2013 were retrospectively evaluated. Ethical approval for the study was obtained. A case file (including the age of first smoking, amount of smoking, smoking status at home and work, alcohol consumption) was prepared for every patient. Routine blood tests (hemogram, liver and renal function tests), electrocardiogram (ECG), and spirometry were performed. The history of comorbidities, like psychiatric illnesses, cardiovascular disease, hypertension, and diabetes mellitus, was questioned. Patients with psychiatric illnesses had a consultation with a psychiatrist before any treatment plan was put in place. The Fagerstrom Nicotine Dependence test was used for quantifying the degree of dependence on tobacco (6). The smoking cessation clinic was run one day every week, and the patients were given a 35 min presentation session regarding smoking cessation. After the presentation, all the patients were evaluated with their case files and laboratory results face-to-face. Monthly control visits were conducted for 6 months and after 2 years all the patients were asked about their smoking status via a telephone call. The smoking cessation status was assessed from the declarations of the patients. Patients who did not attend follow up visits were excluded from the study.

\section{Statistical Analysis}

All of the data from the study were imported to a database formed by the Statistical Package for Social Sciences (SPSS) program V22 (IBM Corp, Armonk, New York, USA), and statistical analysis was also done using the same program. Nominal variables were given by their frequencies and percentages and compared by cross tables. Independent groups were compared using a Chi-square test. The mean, standard deviation, median, minimum, and maximum values of the continuous variables were presented, and the normal distribution of these variables was examined. A normal distribution for all the variables was not present as explored by a normality test, graphical analysis, and by considering the sample size. Comparison of these variables was performed via nonparametric tests. The Mann-Whitney $U$ test was used for the comparison of the independent groups. For all the statistical comparison tests, the probability of a type 1 error was $a=0.05$ and two sided. Differences between the groups were found to be statistically significant if the " $p$ " value was below 0.05 .

\section{RESULTS}

Two hundred and fifty one cases were screened for the study. One hundred and fifty two patients, whose data were eligible and with whom telephone contact was available for organizing control visits, were enrolled in to the study. The average age of the study population was $46.2 \pm 11.2$ (range 18-69). Eighty one (53.3\%) of the patients were female, and 71 patients $(46.7 \%)$ were male. $32.2 \%(n=49)$ of the patients were primary school graduates or at least able to read and write; $17.8 \%(n=27)$ were intermediate school graduates, $27 \%(n=41)$ were high school graduates and $22.4 \%(n=34)$ were university graduates. The average tobacco consumption level of the study population was $27.3 \pm 14.4$ packet years, and patients tried to stop smoking $2.6 \pm 2.1$ times on average. $91.4 \%(n=139)$ declared that they thought about smoking cessation before, $8.6 \%(n=13)$ had already tried and had obtained professional help. The demographic characteristics of the patients are shown in Table 1.

$13.2 \%(n=20)$ of the patients had a diagnosis of chronic obstructive pulmonary disease (COPD), 5.9\% ( $n=9)$ had asthma and $0.7 \%(n=1)$ had cardiovascular disease (CVD). Thirty seven cases $(24.3 \%)$ had a psychiatric illness and 24 cases (15.8\%) had alcohol consumption issues. The distribution of patients who use alcohol or that had a psychiatric illness was similar between the varenicline and bupropion groups ( $\mathrm{p}>0.05)$.

Table 1. Demographic characteristics of the study sample

\begin{tabular}{|l|c|} 
Variables & $\begin{array}{c}\text { Mean } \pm \text { Standard } \\
\text { deviation }\end{array}$ \\
\hline Age & $46.2 \pm 11.2$ \\
Fex (female/male) (n) & $81 / 71$ \\
second (FEV $)(\%)$ & $88.7 \pm 16$ \\
Age of first smoking & $17.6 \pm 5.4$ \\
Amount of current cigarette consumption (n) & $24.3 \pm 11.8$ \\
Years of regular smoking & $28.2 \pm 11.6$ \\
Cigarette consumption (packet.years) & $27.3 \pm 14.4$ \\
Numbers of previous smoking cessation attempts & $2.6 \pm 2.1$ \\
Smoking amount at work & $13.7 \pm 7.4$ \\
Nicotine dependence level & $5.8 \pm 2.3$ \\
\hline Treatment duration (months) & $2.3 \pm 1.4$ \\
Relapse time (months) & $10.2 \pm 6.6$ \\
\hline
\end{tabular}

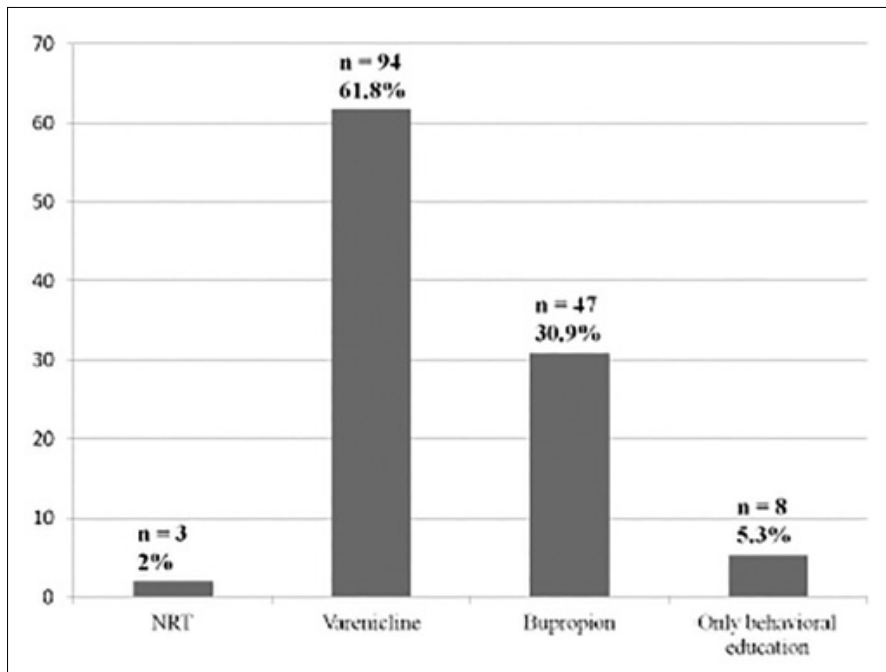

Figure 1. Distribution of treatment modalities used for smoking cessation

NRT: Nicotine replacement therapy 
The nicotine dependence level detected by Fagerstrom questionnaire was $5.8 \pm 2.3$ on average. In addition to the behavioral education, the most preferred treatment modality was varenicline $(n=94$, $61.8 \%$ ), followed by bupropion in $30.9 \%$ of the patients $(n=47)$. Nicotine replacement therapy was the treatment of choice in $2 \%(n=3)$ of patients. In $5.3 \%$ of patients, only behavioral education was given without any pharmacotherapy. The distribution of the treatment modalities in the study population is shown in Figure 1.

Table 2. Comparison of the demographics and follow up characteristics of the varenicline and bupropion groups

\begin{tabular}{|l|c|c|c|}
\hline Variables & $\begin{array}{c}\text { Varenicline } \\
(\mathbf{n}=94)\end{array}$ & $\begin{array}{c}\text { Bupropion } \\
(\mathbf{n}=47)\end{array}$ & $\mathbf{p}$ \\
\hline Age & $46.3 \pm 10.2$ & $46.4 \pm 12.7$ & 0.97 \\
$\begin{array}{l}\text { Forced expiratory volume } \\
\text { in one second (FEV) }(\%)\end{array}$ & $89.4 \pm 14.7$ & $87.4 \pm 19$ & 0.51 \\
\hline First age of smoking & $17.3 \pm 4.4$ & $18 \pm 6.9$ & 0.49 \\
$\begin{array}{l}\text { Amount of current } \\
\text { cigarette consumption (n) }\end{array}$ & $26.9 \pm 13.2$ & $20.5 \pm 7.1$ & 0.002 \\
$\begin{array}{l}\text { Cigarette consumption } \\
\text { (packet.years) }\end{array}$ & $28.7 \pm 15$ & $25.4 \pm 13.3$ & 0.20 \\
$\begin{array}{l}\text { Numbers of previous smoking } \\
\text { cessation attempts }\end{array}$ & $2.7 \pm 2$ & $2.7 \pm 2.5$ & 0.96 \\
$\begin{array}{l}\text { Smoking amount at work } \\
\text { Nicotine dependence level }\end{array}$ & $14.9 \pm 7.6$ & $11.8 \pm 6.8$ & 0.241 \\
\hline $\begin{array}{l}\text { Treatment duration (months) } \\
\text { Relapse time (months) }\end{array}$ & $2.1 \pm 1.3$ & $2.7 \pm 1.4$ & 0.009 \\
\hline
\end{tabular}

When the varenicline and bupropion groups were compared converting the characteristics of the patients, the nicotine dependence levels and currently smoked cigarette amounts were higher in the varenicline group, and this difference was statistically significant (respectively, $p=0.003$ and $p=0.002$ ). Also, the treatment duration was significantly lower in the varenicline group $(p=0.009)$. A comparison of the varenicline and bupropion groups is given in Table 2 .

The smoking cessation rates of the whole population were $61.2 \%$ at 6 months, $34.2 \%$ at 12 months, $18.4 \%$ at 18 months, and $5.3 \%$ at 24 months. There was no difference in smoking cessation rates according to the educational status $(p>0.05)$. There was no difference in smoking cessation rates between the varenicline and bupropion groups ( $p>0.05$ ). A comparison of the varenicline and bupropion groups according to the smoking cessation status is given in Table 3.

Side effects due to pharmacotherapy generally involved only minor side effects. In the varenicline group, one patient used varenicline for 1 month, and myocardial infarction was seen one year after treatment. In another patient, dissection of the aorta was reported after 1 month of treatment with varenicline. Both of the patients survived and the adverse events were not considered as a side effect. Again in the varenicline group, two patients discontinued taking medications due to gastrointestinal side effects. There were no other side effects reported in the study population, except for these four patients.

Because the number of patients given nicotine replacement therapy or only behavioral education was low, these patients were not included in the comparison of the treatment modalities.

Table 3. Comparison of the abstinence rates of the varenicline and bupropion groups

\begin{tabular}{|c|c|c|c|c|c|}
\hline \multirow[b]{2}{*}{ Abstinence } & & & \multicolumn{2}{|c|}{ Treatment } & \multirow[t]{2}{*}{$p$} \\
\hline & & & Varenicline $(n=94)$ & Bupropion $(n=47)$ & \\
\hline \multirow[t]{4}{*}{6 months } & Yes & Number & 60 & 32 & \\
\hline & & $\%$ & 63.8 & 68.1 & \multirow{3}{*}{0.71} \\
\hline & No & Number & 34 & 15 & \\
\hline & & $\%$ & 36.2 & 31.9 & \\
\hline \multirow[t]{4}{*}{12 months } & Yes & Number & 31 & 20 & \\
\hline & & $\%$ & 33.0 & 42.6 & \multirow{3}{*}{0.27} \\
\hline & No & Number & 63 & 27 & \\
\hline & & $\%$ & 67.0 & 57.4 & \\
\hline \multirow[t]{4}{*}{18 months } & Yes & Number & 19 & 8 & \\
\hline & & $\%$ & 20.2 & 17.0 & \multirow{3}{*}{0.82} \\
\hline & No & Number & 75 & 39 & \\
\hline & & $\%$ & 79.8 & 83.0 & \\
\hline \multirow[t]{4}{*}{24 months } & Yes & Number & 5 & 2 & \multirow{4}{*}{1} \\
\hline & & $\%$ & 5.3 & 4.3 & \\
\hline & No & Number & 89 & 45 & \\
\hline & & $\%$ & 94.7 & 95.7 & \\
\hline
\end{tabular}




\section{DISCUSSION}

Tobacco dependence is one of the most important preventable death causes in the world. In various surveys, it has been detected that $70 \%$ of smokers want to quit smoking, and $40 \%$ of them have tried to stop smoking in the previous year and spent at least one day smoke-free (7). However, the one year smoking cessation rate is as low as 3\%-7\% without an appropriate aid. Because of these data, we examined the data relating to smoking cessation carried out in a secondary state hospital and tried to compare the data of patients on different smoking cessation medications. At the end of 1 year, 34.2\% of the study population was still not smoking, whereas at the end of 2 years this ratio decreased to $5 \%$. In addition to behavioral counseling, the most preferred treatment option was varenicline (61.8\%), followed by bupropion (30.9\%). Smoking cessation rates in the varenicline and bupropion groups were similar; however, the varenicline group was composed of patients whose nicotine dependence levels were significantly higher.

Smoking cessation clinics play an important role in tobacco control. With optimal treatment, 1 year abstinence rates after a single quit attempt may exceed $30 \%$ (8). When the studies from Turkey are taken into consideration, Yaşar et al. (9) found 1-year abstinence rates in a smoking cessation clinic of a secondary state hospital as $37.3 \%$. Abakay et al. (10) found $48.8 \%$ success in smoking cessation at the end of 1 year with pharmacotherapy in a university hospital. Argüder et al. (11) reported $36.5 \%$ cessation rates in a tertiary state hospital. Other studies from Turkey generally reported similar 1-year abstinence rates, reaching as high as $45 \%$ (12-14). The 1 year abstinence rate of our study population is also in accordance with these results.

It was estimated that $60 \%-90 \%$ of people that quit smoking restart tobacco use in their first year of abstinence. This ratio is $2 \%-4 \%$ per year between 2 and 6 years of abstinence and decreases to $1 \%$ after 10 years (15). We found relapse rates of $31.6 \%$ in the first 6 months and $58.6 \%$ at the end of one year. The most important determinants of relapse occurring during or after the treatment period are found to relate to pretreatment self-confidence and determination, the affective state at the time of the first cigarette, and the origin of the first cigarette (16). In patients with a high risk of relapse, treatment with a longer duration may be considered, and this may prevent relapses during treatment period (17). In a randomized study, the prolonged duration of varenicline treatment for another 12 weeks significantly increased the 6 months and 1 year abstinence rates (18). However, in our study, we found an increasing relapse rate in 18 and 24 months and at the end of 24 months; $87.5 \%$ of the study population eventually started to smoke again. This ratio is higher than expected according to literature finding. According to these results, for the prevention of late relapses, behavioral counseling methods may be individualized, focusing on the risk and possible future causes of relapses.

Furthermore, for selected cases of combination therapies either within nicotine replacement therapy (NRT) or with NRT or varenicline or bupropion may be borne in mind. Combinations of drugs appear to be more effective than mono-therapy but can also lead to more side effects (19). In a randomized trial, a nicotine patch and varenicline combination was found to be more effective in 6 months treatment compared with varenicline alone (20). The combination of bupropion and varenicline seems to offer higher abstinence rates although the difference was not significant (21). Again there was no significant difference in the rates of abstinence with bupropion and NRT combination than with NRT or bupropion alone (22). The results of the trials are controversial, and there is not enough information about the long-term benefits of combination pharmacotherapy. Furthermore, we did not use combination therapies in our study population.

We did not find any significant difference in abstinence rates between the varenicline and bupropion groups. In two randomized controlled studies with a study population exceeding 2,000, early and late abstinence rates were significantly higher with varenicline compared to bupropion $(23,24)$. Moreover, in the phase II study of Nides et al. (25), smoking cessation rates were higher with varenicline compared with bupropion or a placebo. Our study is an observational study, and the study populations of the varenicline and bupropion groups are different in the case of the smoking amount, treatment duration, and nicotine dependence levels. These may result in similar rates of abstinence and can obscure differences between the treatment choices.

Behavioral counseling without any pharmacological agent was the treatment option in a small percent of cases in our smoking cessation clinic. Meta-analyses of clinical studies have shown that the combined use of pharmacotherapy and behavioral counseling is more efficient than behavioral counseling alone (OR 1.7, 95\% Cl 1.s-1.6) and pharmacotherapy alone (OR 1.4, 95\% Cl 1.2-1.6). Because of this, the combined use of behavioral interventions and pharmacological treatment is advised for the management of smoking cessation (26, 27). In the present study, all the patients received behavioral counseling and pharmacotherapy use was assessed according to the requirements, contraindications, wills, and economical status of the patients.

Our study has some limitations. Mainly as it is a retrospective study, all the patients could not be reached, and there were missing data. Furthermore, CO levels in expired air could not be measured, and the smoking cessation status of the patients could not be objectively assessed.

\section{CONCLUSION}

This study shows that the combined use of pharmacological and behavioral interventions may result in particular success in smoking cessation clinics. Particularly for the prevention of late relapses, the individualized assessment of risk status for relapse and more intensive behavioral counseling for selected cases may be considered. Moreover, treatment durations may be planned to last longer in the population with a high risk of relapse.

Ethics Committee Approval: Ethics committee approval was received for this study from the ethics committee of İmir University.

Informed Consent: Informed consent was not approved by patients, because this was an observational retrospective study.

Peer-review: Externally peer-reviewed.

Author Contributions: Concept - S.D.; Design - S.D.; Supervision - S.D.; Data Collection and/or Processing - S.D., Ö.Ö.; Analysis and/or Interpretation - S.D., Ö.Ö.; Literature Search - J.Ç.E.; Writing Manuscript - S.D., J.Ç.E.; Critical Review - A.B.

Conflict of Interest: No conflict of interest was declared by the authors.

Financial Disclosure: The authors declared that this study has received no financial support. 


\section{REFERENCES}

1. WHO Report on Global Tobacco Epidemic, 2013: enforcing bans on tobacco advertising, promotion and sponsorship. Available from: URL: http://www.who.int/tobacco/global_report/2013/en/ Accessed November 28, 2014.

2. Bilir N, Çakır B, Dağıı E, Ergüder T, Önder Z. Tobacco Control in Turkey. WHO Europe, 2009. Available from: URL: http://www.euro.who.int/_data/assets/pdf_file/0004/98446/E93038.pdf Accessed November 1, 2014.

3. WHO Report on Global Tobacco Epidemic, 2008: Mpower package. Available from: URL: http://www.who.int/tobacco/mpower/2008/en/ Accessed November 28, 2014.

4. Global Adult Tobacco Survey Turkey Report 2008. Ministry of Health, Publication No: 803, Ankara, 2010.

5. Global Adult Tobacco Survey Turkey Report 2012. Ministry of Health, Publication No: 948, Ankara, 2014.

6. Heatherton TF, Kozlowski LT, Frecker RC, Fagerström KO. The Fagerstrom Test for Nicotine Dependence: a revision of the Fagerstrom Tolerance Questionnaire. Br J Addict 1991; 86: 1119-27. [CrossRef]

7. Rigotti NA. Clinical practice. Treatment of tobacco use and dependence. N Engl J Med 2002; 346: 506-12. [CrossRef]

8. Fiore MC, Jaén CR, Baker TB, Bailey WC, Benowitz NL, Curry SJ, et al. Treating Tobacco Use and Dependence: 2008 Update. Clinical Practice Guideline. Rockville, MD: U.S. Department of Health and Human Services. Public Health Service. May 2008.

9. Yaşar Z, Kurt ÖK, Talay F, Kargı A. One-year follow up results of smoking cessation outpatient clinic: Factors affecting the cessation of smoking. Eurasian J Pulmonol 2014; 16: 99-104. [CrossRef]

10. Abakay Ö, Abakay A, Tanrıkulu AÇ, Şen HS, Sezgi C, Dallı A, et al. The outcome of patients that admitted to outpatients of smoking cessation. J Chest Dis Crit Care Med 2014; 1: 7-10. [CrossRef]

11. Argüder E, Karalezli A, Hezer H, Kilıç H, Er M, Hasanoğlu HC, et al. Factors affecting the success of smoking cessation. Turk Thorac J 2013; 14: 81-7. [CrossRef]

12. Sağlam L. Investigation of the results of a smoking cessation clinic and the factors associated with success. Turk J Med Sci 2012; 42: 515-22.

13. Çan G, Öztuna F, Özlü T. The evaluation of outpatient smoking cessation clinic results. Tuberc Thorax 2004; 52: 63-74.

14. Salepçi B, Fidan A, Oruç Ö, Torun E, Çağlayan B, Kader ŞN. Success rates in our smoking cessation clinic and factors affecting it. Turk Thorac J 2005; 6: 151-8.

15. Krall EA, Garvey AJ, Garcia RI. Smoking relapse after 2 years of abstinence: findings from the VA Normative Aging Study. Nicotine Tob Res 2002; 4: 95-100. [CrossRef]

16. Brandon TH, Tiffany ST, Obremski KM, Baker TB. Postcessation cigarette use: the process of relapse. Addict Behav 1990; 15: 105-14. [CrossRef]
17. Hawk LW Jr, Ashare RL, Lohnes SF, Schlienz NJ, Rhodes JD, Tiffany ST, et al. The effects of extended pre-quit varenicline treatment on smoking behavior and short-term abstinence: a randomized clinical trial. Clin Pharmacol Ther 2012; 91: 172-80. [CrossRef]

18. Tonstad $S$, Tonnesen $P$, Hajek $P$, Williams KE, Billing CB, Reeves $K R$, et al. Effect of maintenance therapy with varenicline on smoking cessation: a randomized controlled trial. JAMA 2006; 296: 64-71. [CrossRef]

19. Piper ME, Smith SS, Schlam TR, Fiore MC, Jorenby DE, Fraser $D$, et al. A randomized placebo-controlled clinical trial of 5 smoking cessation pharmacotherapies. Arch Gen Psychiatry 2009; 66: 1253-62. [CrossRef]

20. Koegelenberg CF, Noor F, Bateman ED, Van Zyl-Smit RN, Bruning A, $\mathrm{O}$ 'Brien JA, et al. Efficacy of varenicline combined with nicotine replacement therapy vs. varenicline alone for smoking cessation: a randomized clinical trial. JAMA 2014; 312: 155-61. [CrossRef]

21. Ebbert JO, Hatsukami DK, Croghan IT, Schroeder DR, Allen SS, Hays JT, et al. Combination varenicline and bupropion SR for tobacco-dependence treatment in cigarette smokers: a randomized trial. JAMA 2014; 311: 155-63. [CrossRef]

22. Stapleton J, West R, Hajek P, Wheeler J, Vangeli E, Abdi Z, et al. Randomized trial of nicotine replacement therapy (NRT), bupropion and NRT plus bupropion for smoking cessation: effectiveness in clinical practice. Addiction 2013; 108: 2193-201. [CrossRef]

23. Gonzales D, Rennard SI, Nides M, Oncken C, Azoulay S, Billing CB, et al. Varenicline Phase 3 Study Group. Varenicline, an alpha4beta2 nicotinic acetylcholine receptor partial agonist, vs sustained-release bupropion and placebo for smoking cessation: a randomized controlled trial. JAMA 2006; 296: 47-55. [CrossRef]

24. Jorenby DE, Hays JT, Rigotti NA, Azoulay S, Watsky EJ, Williams KE, et al. Varenicline Phase 3 Study Group. Efficacy of varenicline, an alpha4beta2 nicotinic acetylcholine receptor partial agonist, vs placebo or sustained-release bupropion for smoking cessation: a randomized controlled trial. JAMA 2006; 296: 56-63. [CrossRef]

25. Nides M, Oncken C, Gonzales D, Rennard S, Watsky EJ, Anziano N, et al. Smoking cessation with varenicline, a selective alpha4beta2 nicotinic receptor partial agonist: results from a 7-week, randomized, placeboand bupropion-controlled trial with 1-year follow-up. Arch Intern Med 2006; 166: 1561-8. [CrossRef]

26. Stead LF, Lancaster T. Combined pharmacotherapy and behavioral interventions for smoking cessation. Cochrane Database Syst Rev 2012; 10:CD008286.

27. Suls JM, Luger TM, Curry SJ, Mermelstein RJ, Sporer AK, An LC. Efficacy of smoking-cessation interventions for young adults: a meta-analysis. Am J Prev Med 2012; 42: 655-62. [CrossRef] 